\title{
View to the Past
}

\author{
Irene Brown \\ Fine Art Department \\ Newcastle University, UK \\ Irene.brown@ncl.ac.uk
}

\begin{abstract}
As artist in residence at the Thackray Medical Museum, Leeds in 2016 I produced View to the Past, an art installation consisting of five custom-made virtual reality viewers, placed at strategic points throughout the museum and three augmented reality postcards for sale in the shop. The commission brief was to reflect two significant but underrepresented periods in the building's history; its original use as the Leeds Union Workhouse and its time as the East Leeds War Hospital during World War I (WWI).
\end{abstract}

Virtual Reality. Augmented Reality. Museum. Contemporary art.

\section{INTRODUCTION}

The residency was commissioned $(£ 8,000)$ as part of Meeting Point - a twelve-month project led by contemporary art specialists Arts\&Heritage (http://www.artsandheritage.org.uk/meeting-point/). Leading UK and international artists were partnered with nine museums in the North East and Yorkshire to produce new artworks inspired by the museums and their collections. Funded by Arts Council England's Museum Resilience Fund, Meeting Point presents artworks in unexpected places and supports small and medium-scale museums to commission artists to create work in response to the venue. The project aims to bring new visitors to the participating museums and position them as exciting places to see contemporary art. Judith King, director at Arts\&Heritage,

\begin{abstract}
Meeting Point addresses the fundamental question of why museums and the contemporary arts should work together. The potential benefits of placing new and exciting artworks in museum and heritage venues are huge, not only for the artists and the venues but for the museum visitors, who will encounter a new way of experiencing history and their collections.
\end{abstract}

The Thackray is a history of medicine museum on the site of St James's University Hospital in Leeds. Attracting over $65 \mathrm{k}$ visitors a year, it is housed in a grade II listed building, the former Leeds Union Workhouse, built in 1858. During the First World War it was the East Leeds War Hospital caring for armed services personnel. It became the Thackray Medical Museum in 1997, named after Leeds- based international surgical instrument company of the same name. Historic instrumentation makes up the bulk of the artefacts in the museum collection.

The museum attracts a diverse range of visitors including medical professionals attending conferences, families, school groups, medical students and organised outings for specialised interest groups. Externally it presents an anonymous but imposing edifice. Internally most of the original history of the building has been removed or is hidden behind permanent displays and is not immediately evident.

\section{THE COMMISSION}

The museum sought an artist who would spend time in residence, familiarising themselves with the museum, its people and its past. The project would need to engage with visitors and staff creating a focus point, generating information and conversations on a subject that has very little representation in the existing displays.

My own background is as an artist who specialises in site-specific installations. My current research and practice is focused on the history of science, in particular, wonder and visual display - investigating the threshold between aesthetic and scientific realms. My working methods include sculpture, photography and video, and artworks often include kinetic elements and optical illusions.

This, however, was my first experience of using digital methodologies. Part of the ethos of my 
approach was to explore the creative potential of technology that is simple, free and widely available. The magic here is not the artist's technical genius (this I am certainly not), or the mysteries of expensive and unfathomable programmes but in the imaginative use of accessible, user-friendly systems.

\subsection{Historical Research}

The museum, its archives and library contain extensive information and artefacts concerning the history of medicine, but little that can be directly linked to when it was a World War 1 Hospital. As for its time as a workhouse, everything was destroyed long ago. The stigma carried by such places and the poor quality of any associated artefacts most often results in any records, furniture, artefacts etc. being destroyed. There is only one remaining image attributed to the Leeds Union Workhouse - that of the able-bodied female inmates in 1920, dressed in a distinctive striped uniform

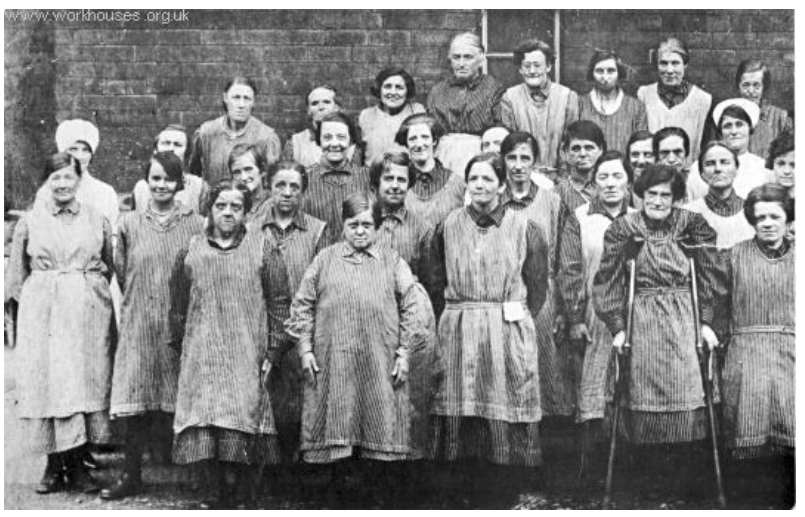

Figure 1: Able-bodied female inmates of the Leeds Union workhouse c.1920.

Courtesy of the Thackray Museum archives.

The project therefore required a great deal of research involving historians, museums and archives across the country in order to gradually piece together some of the missing components of the Thackray's past. Visits to workhouse museums in Ripon and Southwell, information from the South West Heritage Trust in Somerset and the Fashion Museum in Bath, gradually built a visual archive used to help create the artworks. Further exploration unearthed long lost plans of the interior layout of the original workhouse, and the Thackray archives provided some material on WWI Hospitals, including a small collection of photographs and some period 'props' for use in staging the photo shoots.

\subsection{VR Viewers}

The VR viewers were designed to act as time machines. Presenting an unsettling $360^{\circ}$ view into the past and magically revealing what the building once looked like, the ghosts of those who previously inhabited it seem to surround and observe you.

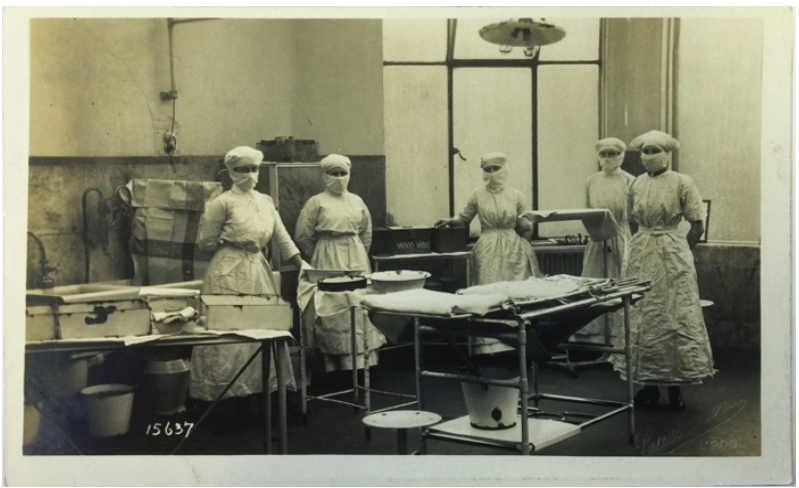

Figure 2: A postcard of Surgery Nurses in an operating theatre c1914. Courtesy of the Thackray Museum archives.

In the museum galleries, a WWI operating theatre, with nurses and doctors and patients appear, along with the workhouse laundry. The corridors house a 1914 hospital ward and a scene from the male wing of the $19^{\text {th }}$ century workhouse. And in the ornate entrance hall, one of the few remaining original architectural features inside the building, the workhouse Board of Guardians can be seen visiting.

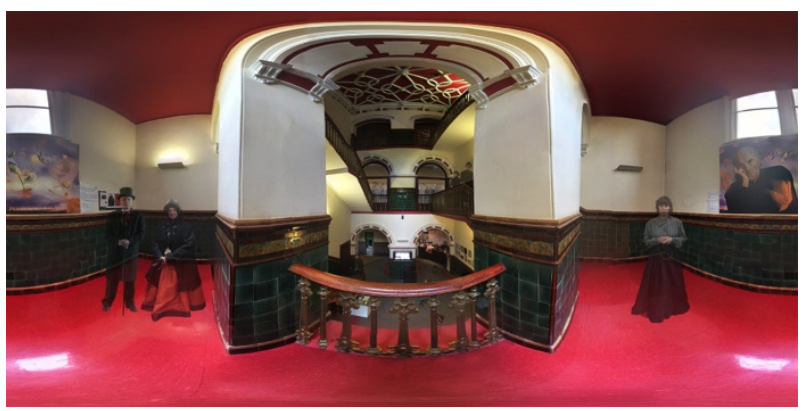

Figure 3: Photosphere of the Workhouse Governor's Visit. Courtesy of the Thackray Museum archives.

Each of the five VR devices, constructed to house either an iPhone or iPad, was individually designed and built to reflect a specific period of the building's history. Incorporating materials scavenged from the museum's handling collection (damaged wooden instrument cases and duplicate implements), their shape was inspired by early optical devices such as original stereoscopes and graphoscopes. The VR devices had to be able to withstand some rough treatment over an extended period - approximately 27,000 visitors over the five months of the exhibition. Each device was connected to a wall or balustrade-mounted holder by an umbilical cord that carried a power conduit and security cable. 


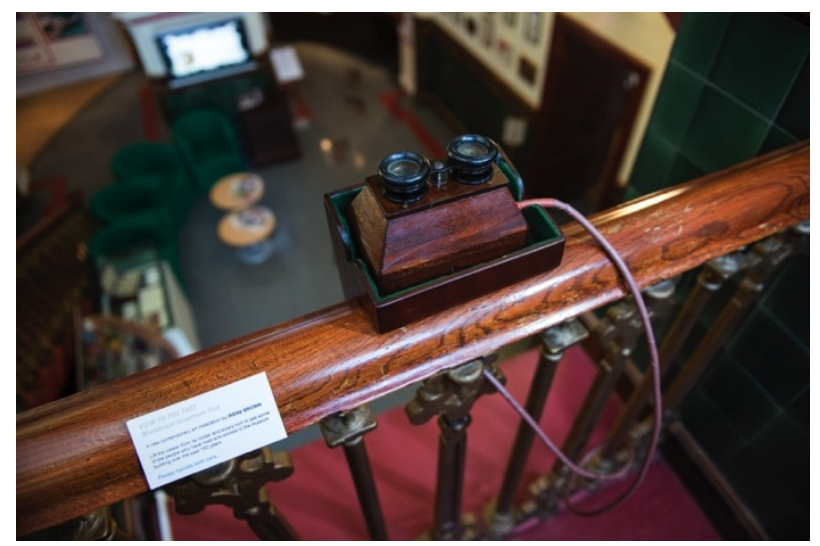

Figure 4: Workhouse Governor's Visit VR viewer housing an iPhone 6.

\subsection{Methodology}

Firstly, identifying the exact location in the museum for positioning each viewer, I made a $360^{\circ}$ photosphere of the site using the Google Street View app on my iPhone $6 \mathrm{~S}$ plus. Importing these into Photoshop I repaired any misalignments or fractures in the 'stitching' of the photospheres.

I then organised a three-day photo shoot, constructing a huge green-screen $(6 \times 8 \mathrm{~m})$ in one of the education rooms in the Thackray and staging scenes using personally sourced items and artefacts borrowed from the Thackray collection. Volunteers from the museum participated enthusiastically. Acting as photographic models, and wearing meticulously sourced period clothes or specially made historic reproduction costumes, they provided the ghostly historic characters populating the viewers and postcards.

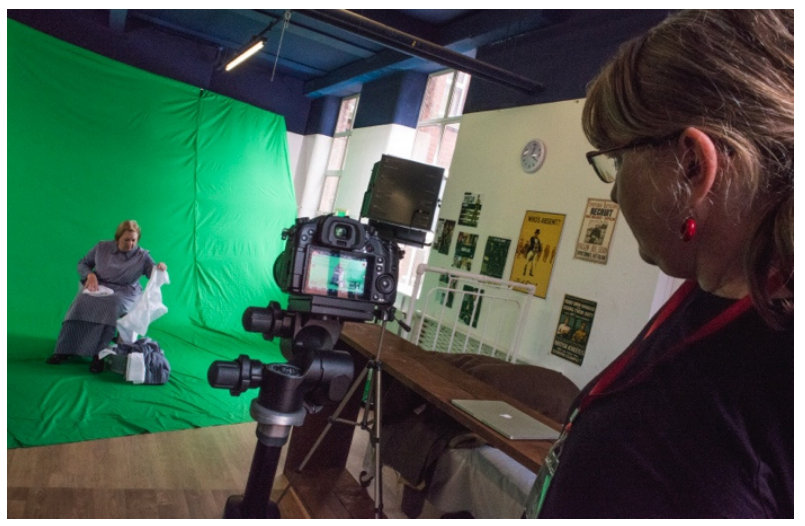

Figure 5: Green-screen photo shoot with volunteer, Pat Daly.

These portraits, along with other images taken of workhouse museums in Ripon and Southwell, were then added to the photospheres using Photoshop and the document saved as a Jpeg with the prefix PANO. This ensured that all the metadata and the 3D information stayed with the file. Each edited photosphere was then uploaded onto an iPad or
iPhone housed in one of the VR devices and viewed via Google Street View. The device was then sited back in the exact location that the original photosphere was taken and aligned to match the orientation of the room.

Looking through the device presented the illusion that the viewer could see the room not as it is now, but at a different point in its history. Vinyl floors became stone flags, photographic displays melted into whitewashed walls, and the phantoms of past inhabitants were suddenly visible.

Only two of the viewers employed an immersive VR stereoscopic system, using the Google Cardboard option in Google Street View on an iPhone. The other three viewers presented one image on an iPad, employing the Google Street View 'compass' option to navigate the photosphere. This was to give an alternative way for visitors to access the experience, including those for instance, with visual impairment or glasses who might find it difficult use or focus the stereoscopic viewers.

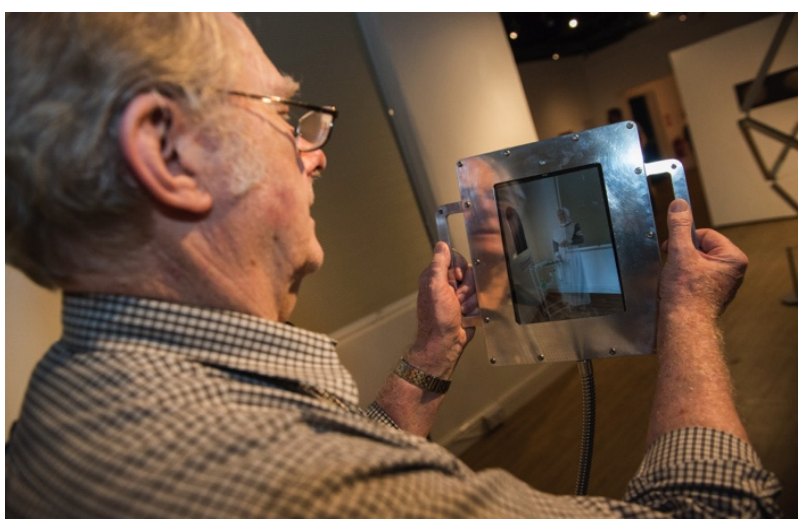

Figure 6: WWI Operating Theatre VR viewer housing an iPad.

\section{AUGMENTED REALITY POSTCARDS}

The three Augmented Reality postcards echo the scenarios in the VR devices. Made using the free online Aurasma Studio and viewed via the Aurasma app, they are digital prints - static images that come to life when viewed through a smartphone or tablet. Pointing the camera of an android-based mobile device at a 'trigger image' (a photograph) that has an 'overlay' (a video) attached initiates the sequence, appearing to animate the image.

The trigger images used for the AR postcards were the first frame of three short videos (20 seconds) depicting scenes in a 1920s-workhouse laundry, a late nineteenth century workhouse men's ward and a World War I (WWI) Operating Theatre. In addition to the still portraits taken for use in the VR viewers, a short video of each character was also shot 
against the green-screen - folding washing, scrubbing floors, rolling bandages, performing surgery etc. Using Adobe After Effects, several video sequences were combined to create a busy scene, set against a photosphere backdrop. This video overlay was uploaded in Aurasma Studio and carefully resized to exactly match the format of the trigger image. It is this precise alignment of trigger image to video overlay that enhances the magical effect of the postcard coming alive. The file was saved, 'shared' and viewed by subscribing to the free Aurasma app, creating an account and 'Following' the Thackray Public Auras.

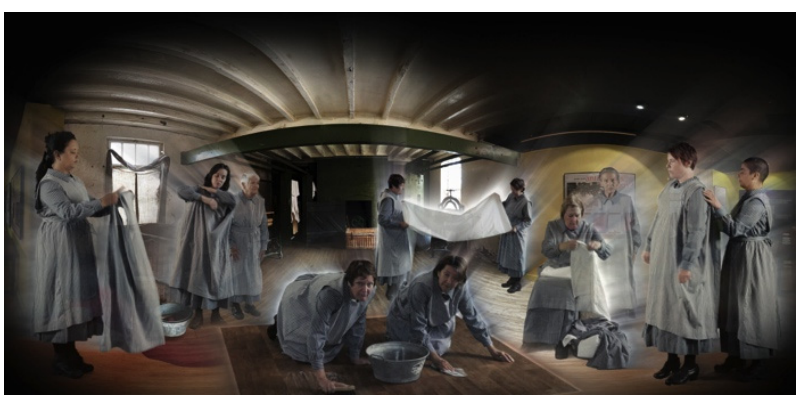

Figure 7: Workhouse Laundry Augmented Reality Postcard trigger image.

\section{THE PAST LOOKS BACK}

A critical concern was that a strong connection should be made between the viewer and the viewed. The characters from the past did not go about their business, ignorant of the fact that the VR viewers or AR postcards made them visible. The unsettling quality of the work was enhanced by the sensation that the devices and postcards permitted a two-way visibility. The 'ghosts' seen through the VR viewers appeared to be standing a little too close, examining you with as much curiosity as you them. In the VR postcards, the characters all gradually stop what they are doing and look straight into the camera; one even walks forwards and looks directly into the lens, seeming to openly confront you.

You look at the past and the past looks back, encouraging empathetic connections across time. There is recognition, enhanced by the involvement of the volunteers that these people of the past are not unlike us; they are us. The extremes of the workhouse may no longer exist but the stigma attached to them is still within living memory. Concerns of how we address poverty, care for the elderly and treat the mentally ill continue to be extremely pertinent issues. Over 100 years has passed since WWI but facilities to treat the injuries of warfare remain indispensable. Accessible, engaging and magical the work may be, but it is also unsettling and thought provoking.

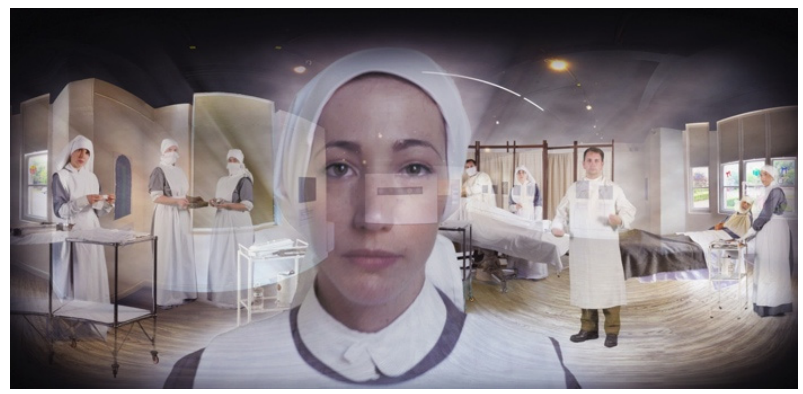

Figure 8: WWI Operating Theatre Augmented Reality Postcard video overlay.

\section{EVALUATION}

The VR devices needed regular adjustment and repair. As temporary artworks, rather than permanent museum exhibits, they were susceptible to the harsh environment and extended heavy footfall. Cables were worn and Google Street View independently misaligned the photosphere from time to time and had to be reset. A far more robust and therefore possibly less visually creative, and clearly much more expensive system, would need to be used for any future installation in a similar environment.

The AR Postcards were very effective and continue to be a popular purchase in the museum shop. I have since tested Aurasma app in workshops involving participants aged from 8 - 80, and everyone with an up-to-date android phone or tablet finds accessing and using the app easy and exciting. This system has a great deal of potential for further use in museums and other educational environments. Resourcing the costumes and making the videos was the most expensive aspect of producing the postcards for this project, but this could also be relatively inexpensive - depending on the subject matter.

The potential benefits of both approaches - the Aurasma App and VR viewers are huge - not only for artists and venues but for audiences, who encounter a new way of experiencing art and museum collections by engaging with contemporary devices of wonder. 